\title{
Influence of different loading paths on the multiaxial fatigue behavior of 2024 aluminum alloy under the same amplitude values of the second invariant of the stress deviator tensor
}

\author{
A.S. Yankin, A.I. Mugatarov, V.E. Wildemann \\ Center of Experimental Mechanics, Perm National Research Polytechnic University, Perm, Russian Federation \\ yas.cem@yandex.ru, https://orcid.org/0000-0002-0895-4912 \\ cem_mugatarov@mail.ru, bttps://orcid.org/0000-0002-2229-8181 \\ wildemann@pstu.ru,https://orcid.org/0000-0002-6240-4022
}

ABSTRACT. 2024 aluminum alloy is a common aeronautic material. During operations, construction elements made of aluminum alloys undertake complex cyclic loadings. Therefore, it is important to estimate the influence of these loadings on the durability of the material. Hereby, multiaxial fatigue tests with the same amplitude values of the second invariant of the stress deviator tensor are conducted, and test data are analyzed. The modified Sines method is utilized to predict fatigue experimental data. Results show that the model is accurate enough to fatigue behavior prediction of 2024 aluminum alloy.

KEYWORDS. Multiaxial fatigue; Tension; Torsion; 2024 aluminum alloy.

\section{OPEN ACCESS}

Citation: A.S. Yankin, A.I. Mugatarov, V.E. Wildemann, Influence of different loading paths on the multiaxial fatigue behavior of 2024 aluminum alloy under the same amplitude values of the second invariant of the stress deviator tensor, Frattura ed Integrità Strutturale, 55 (2021) 327-335.

Received: 16.12 .2020 Accepted: 24.12 .2020 Published: 01.01.2021

Copyright: (C) 2021 This is an open access article under the terms of the CC-BY 4.0, which permits unrestricted use, distribution, and reproduction in any medium, provided the original author and source are credited.

\section{INTRODUCTION}

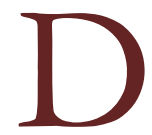

uring operations the greatest number of critical components of construction elements undertake complex cyclic loadings, thus the estimation of their influence on the durability of metal materials is a problem to be solved [14]. Also, the need in studying fatigue processes under complex stress state brought a number of experimental works in this area, which used specialized equipment and methods of multiaxial loading.

The main loading conditions referred to the literature when studying multiaxial fatigue are biaxial tension of cross-shaped specimens, tension with torsion and bending with torsion of cylindrical specimens. Meanwhile, attention is paid not only to the proportional cyclic loading but also to more complex modes with phase shifting, different frequencies and other characteristics [5-9]. Apart from testing standard hourglass and tubular specimens, one can also test weld joint specimens $[10,11]$, specimens with grooves [12] and other stress raisers [13]. 
There are a large number of factors that can influence the fatigue behavior of materials under the multiaxial influence. These include the change in the ratio of stress amplitudes [14-16], the phase angle between the modes of influence [14-17], the ratio of loading frequencies [18-19], average stresses in the cycle [20-24] and others. Moreover, real structures have a complex geometry and consequently stress raisers that might influence the fatigue resistance. Also, notches are a reason of inherent multiaxiality [25]. In this case, even if the loading is uniaxial, the stress or strain fields in the vicinity of stress or strain raiser are multiaxial.

For different materials, different dependencies of fatigue behavior on loading factors can be observed. For example, an increase in the mean stress leads to a decrease in fatigue strength. This effect is quite strong for brittle materials (e.g. cast iron) both in axial and in torsion [26]. However, this effect is lower in torsion than in axial for ductile materials such as steels and aluminum alloys [27].

Nowadays, there are different criteria of multiaxial fatigue that can be used to describe the regularities of the fatigue behavior of various materials. These approaches can be classified as energy-based, based on a critical plane and static criteria. Also, probabilistic fatigue models should be noted that allow taking into account different sources of uncertainty in prediction such as material properties and microstructures (e.g. large inclusions or defects) or geometrical features of structures. The most frequently mentioned models in the literature include the Fatemi - Socie [28], Smith - Watson - Topper [29], Brown Miller [30], Crossland [31], Sines [22], generalized strain energy/amplitude [32] methods and various their modifications [20, $27,33,34]$. Some reviews of multiaxial criteria are presented in works [35, 36]. All these approaches might be more or less accurate for various materials at different loading paths, therefore it is important to validate multiaxial fatigue models in particular cases. In addition, it is also important to check the applicability of models for notched and cracked bodies.

In previous work, the Marin, modified Crossland and Sines models were compared by using non-proportional fatigue test data (with superimposed static mean stress) of 2024 aluminum alloy [37]. As a result, it was shown that the modified Sines method described the experimental data in the most accurate way. The present work is aimed at checking the modified Sines method by means of biaxial fatigue data of the 2024 aluminum alloy at the different ratio of stress amplitudes, angle of phase shift between the modes of influence and ratio of frequencies of biaxial (tension-compression and torsion) influences.

\section{EXPERIMENTS}

\section{Material and specimen}

7 xperimental studies to assess the durability of metallic materials under multiaxial cyclic loading were carried out on 1 samples of the 2024 aluminum alloy, manufactured taking into account the requirements of GOST 25.502. The 2024 alloy is one of the main structural materials in aviation, astronautics and other areas of mechanical engineering and is often used in various tests for fatigue life [38-41].

The chemical composition of the alloy consists of $\mathrm{Cu} 4.28, \mathrm{Mg} 1.48, \mathrm{Mn} \mathrm{0.75,} \mathrm{Fe} \mathrm{0.28,} \mathrm{Si} \mathrm{0.29,} \mathrm{Zn} \mathrm{0.12,} \mathrm{Ni} \mathrm{0.009,} \mathrm{Ti} \mathrm{0.06,}$ $\mathrm{Cr} 0.017, \mathrm{~Pb}$ 0.05. Mechanical properties for the material are listed in Tab. 1. Fatigue tests were performed on hourglass specimens. The specimen geometry is shown in Fig. 1. The specimens are designed in accordance with recommendations of national standard GOST 25.502. Stresses used in calculating were in accordance with the minimum cross-section of specimen.

\begin{tabular}{cccc}
\hline Property & Symbol & 2024 aluminum alloy & Unit \\
$0.2 \%$ Tensile yield strength & $\sigma_{y}$ & 336 & $\mathrm{MPa}$ \\
$0.3 \%$ Torsional yield strength & $\tau_{y}$ & 153 & $\mathrm{MPa}$ \\
Modulus of elasticity & $E$ & 75.4 & $\mathrm{GPa}$ \\
Shear modulus & $G$ & 30.0 & $\mathrm{GPa}$ \\
Shear fatigue strength coefficient & $\tau_{f}^{\prime}$ & 445 & $\mathrm{MPa}$ \\
Shear fatigue strength exponent & $b_{0}$ & -0.0765 & $\mathrm{MPa}$ \\
Fatigue strength coefficient & $\sigma_{f}^{\prime}$ & 1290 & \\
Fatigue strength exponent & $b$ & -0.1254 & \\
\hline
\end{tabular}

Table 1: Mechanical properties of 2024 aluminum alloy. 


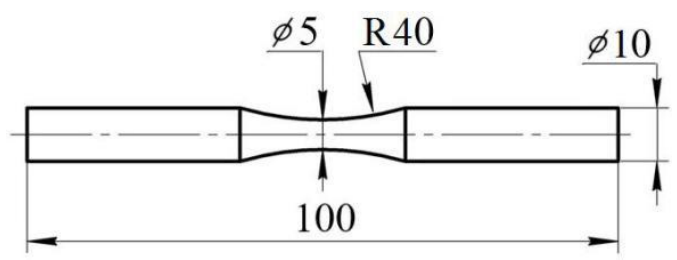

Figure 1: Specimen geometry (in $\mathrm{mm}$ ).

\section{Experimental procedure and results}

All tests were carried out in the Instron ElectroPuls E10000 at room temperature in the Center of Experimental Mechanics (Russia). The ElectroPuls E10000 Linear-Torsion is an all-electric test instrument with a dynamic linear load capacity of $\pm 10 \mathrm{kN}$ and a dynamic torque capacity of $\pm 100 \mathrm{Nm}$. More information you can find in [21].

As part of the work, fatigue tests were carried out to determine the durability of the 2024 aluminum alloy at various values of the ratio of stress amplitudes, the angle of phase shift between the modes of influence and the ratio of the frequencies of biaxial loading. Thus, the study concentrates on uniaxial under tension-compression or torsion and multiaxial loading situations involving mixtures of tension-compression and torsion (out-of-plane shear): mode I and mode III in the terminology of fracture mechanics. The loading conditions and the results of the experiments are shown in Tab. 2. In all experiments, the amplitude of equivalent von Mises stress, $\sigma_{\mathrm{Ma}}=\left(\sigma_{\mathrm{a} 2}+3 \tau_{\mathrm{a} 2}\right)^{1 / 2}$, was the same. The average number of cycles

before failure was determined by the formula $N_{50}=10^{\frac{1}{n} \sum_{i=1}^{n} \log \left(N_{i}\right)}$.

The fatigue curves obtained in tension-compression and torsion for an aluminum alloy have different slope angles [14, 20, 42], that is, the ratio $\sigma_{\mathrm{a}}\left(N_{\mathrm{i}}\right) / \tau_{\mathrm{a}}\left(N_{\mathrm{i}}\right)$ is not constant. This means that for the same values of the stress amplitude, $\sigma_{\mathrm{Ma}}$, the number of cycles before failure can be different. The results presented in this article do not contradict the above. Thus, from Tab. 2 (loadings 1-15) it can be seen that with proportional loadings with the same values of the stress amplitude, $\sigma_{\mathrm{Ma}}$, with an increase in the angle between the normal and share axes, the average number of cycles before failure increases almost in 3 times.

$N_{\text {ex }}$ is the experimental fatigue life, $N_{\mathrm{pr}}$ is the predicted fatigue life according to the Sines ++ model, $\tau_{\mathrm{a}}$ is the amplitude of share stress, $\sigma_{\mathrm{a}}$ is the amplitude of normal stress, $\varphi$ is the phase shift angle between loading modes, $\nu_{\tau}$ is the frequency of loading in the shear mode, $v_{\sigma}$ is loading frequency in the normal mode.

If we plot the fatigue curves obtained in tension-compression and torsion, in the form of the dependence of the amplitude on the number of cycles before failure $\sigma_{\mathrm{Ma}}(N)$, then the curves intersect at the point where $\sigma_{a}\left(N_{1}\right)=\sqrt{ } 3 \tau_{a}\left(N_{1}\right)$. This is the only point where the number of cycles to failure will be constant for the same amplitude values, $\sigma_{\mathrm{M} a}$, for proportional loadings.

The data from Tab. 2 (loads 5-8 and 16-23) show the dependence of the number of cycles to failure on the phase angle between the loading modes. With an increase in the phase shift angle from 0 to 45 degrees, an increase in the number of cycles is observed by about 1.4 times, with an increase to 90 degrees, a return to approximately the original values is observed. The results, available in the literature, show different patterns. Thus, in [17, 38, 42], with an increase in the phase shift angle, a decrease in the number of cycles was observed, in [14], an increase, and in [20], no significant changes were observed. It should be noted that the alloys presented in $[14,17,20,38,42]$ were similar in composition, but differed in heat treatment. The final part of the study was aimed at studying the effect of changing the frequency ratio of biaxial loading on fatigue life. For loadings 5-8 and 24-28 from Tab. 2, it can be seen that in one cycle a load with the same maximum values of the second invariant of the stress deviator tensor acts on the sample, but the loading paths are different (for 24-28 from Tab. 2, the path is more complicated). Due to the complication of the type of impact, there is a decrease in the number of cycles to destruction by about 2.3 times.

Fig. 2 shows typical photographs of fractures of fractured specimens for different loading cycles. Fatigue tests for uniaxial tension-compression (Fig. 2 a) are characterized by a complex fracture with sections located at angles of $90^{\circ}$ and $45^{\circ}$ to the sample axis. Tests for proportional tension-compression with torsion are characterized by a complex fracture, located at an angle of about $45^{\circ}$ to the sample axis (Fig. $2 \mathrm{~b}, \tau_{\mathrm{a}}=116 \mathrm{MPa}, \sigma_{\mathrm{a}}=180 \mathrm{MPa}$ ) and about 80-90 ${ }^{\circ}$ to the sample axis (Fig. $2 \mathrm{c}$, $\tau_{\mathrm{a}}=147 \mathrm{MPa}, \sigma_{\mathrm{a}}=90 \mathrm{MPa}$ ). In pure torsion, the fracture is perpendicular to the rod axis (Fig. $2 \mathrm{~d}$ ). With a phase shift of $90^{\circ}, 45^{\circ}$ and loading with different frequencies of the normal and tangential components, complex fractures are observed, shown in Figs. 2 e-g. 


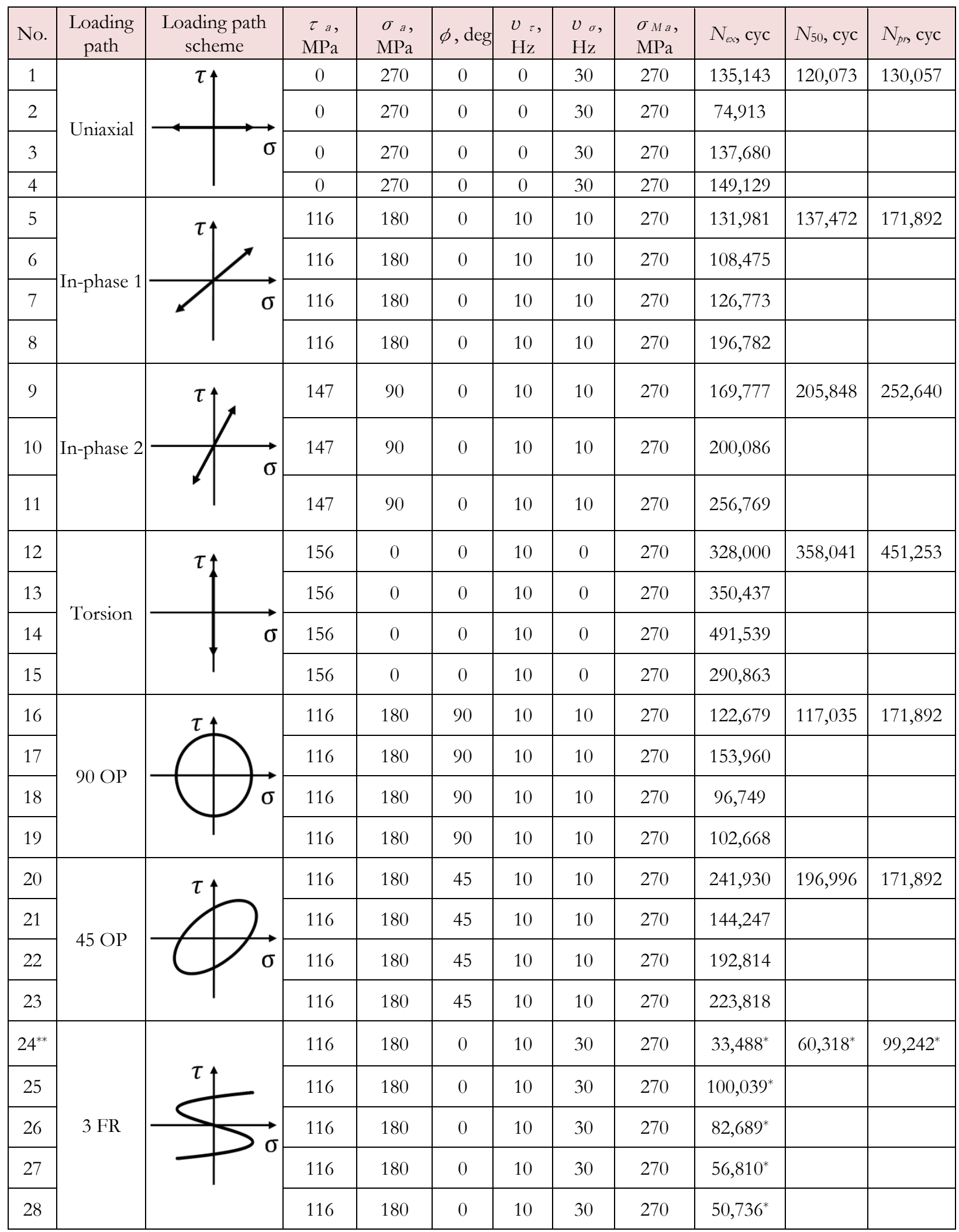

Table 2: Summary of fatigue tests. (For loadings 24-28, cycles were counted in a tangential mode; Test result No. 24 is outside the $\pm 2-$ factor error). 

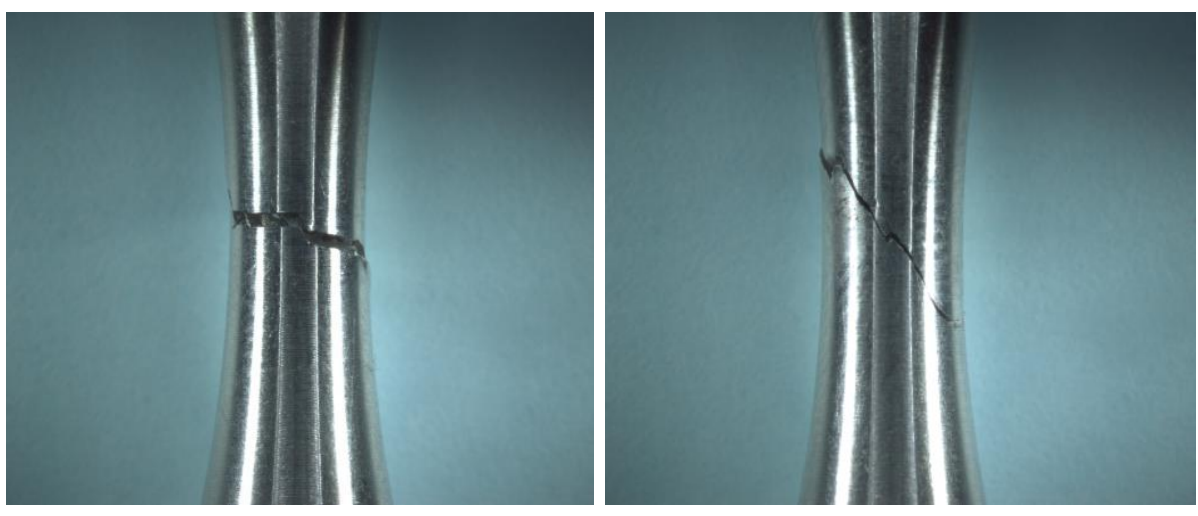

a

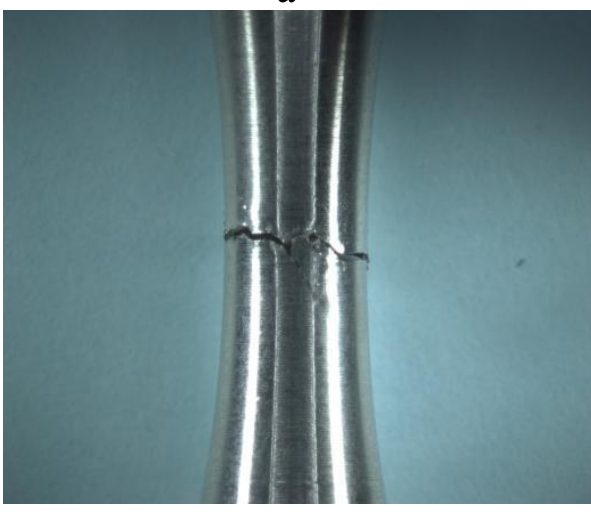

b

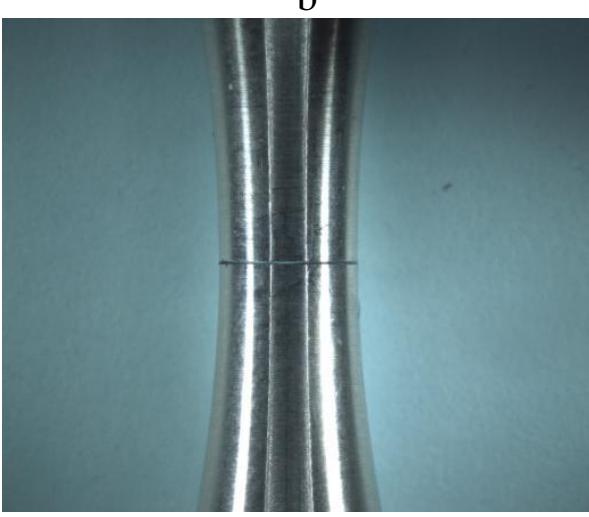

C

d
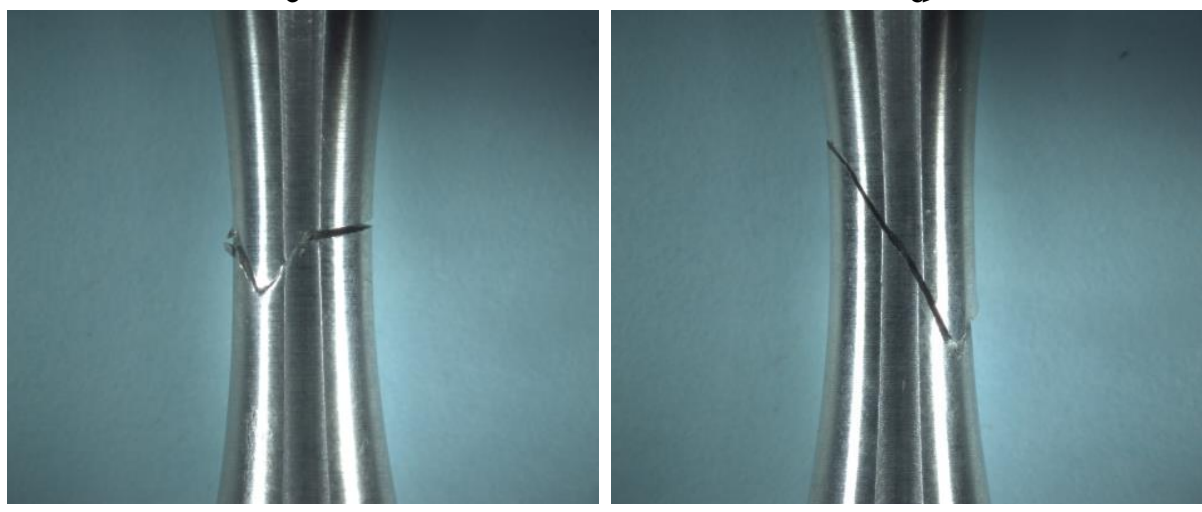

e

f

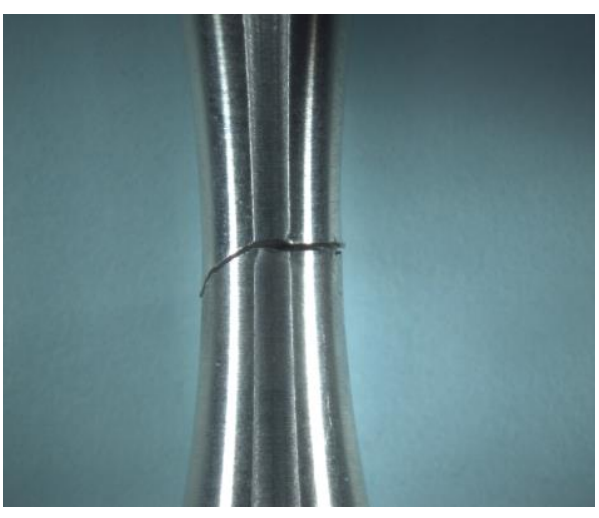

g

Figure 2: Specimens after fatigue failure. 
In the article [37], the authors considered multiaxial fatigue models and compared them based on the results of biaxial nonproportional tests with a constant component of the shear and normal loading axes. Among the models, the most accurate is the modified Sines ++ model. This model allows to take into account the beneficial effect of the mean compressive axial stresses, the higher mean stress effect in the axial direction compared with the torsion case and different slopes of the S-N curves under tension-compression and torsion. Simplistically, the model can be represented as follows:

$$
\begin{aligned}
& \sqrt{\left(A \sqrt{I_{2 a}}\right)^{2}+\left(B \sqrt{I_{2 m}}\right)^{2}}+C I_{1 m}+D I_{1 a} \leq 1 \\
& \sqrt{I_{2 a}}=\frac{1}{\sqrt{6}} \sqrt{\left(\sigma_{11 a}-\sigma_{22 a}\right)^{2}+\left(\sigma_{22 a}-\sigma_{33 a}\right)^{2}+\left(\sigma_{11 a}-\sigma_{33 a}\right)^{2}+6\left(\tau_{12 a}^{2}+\tau_{23 a}^{2}+\tau_{13 a}^{2}\right)} \\
& \sqrt{I_{2 m}}=\frac{1}{\sqrt{6}} \sqrt{\left(\sigma_{11 m}-\sigma_{22 m}\right)^{2}+\left(\sigma_{22 m}-\sigma_{33 m}\right)^{2}+\left(\sigma_{11 m}-\sigma_{33 m}\right)^{2}+6\left(\tau_{12 m}^{2}+\tau_{23 m}^{2}+\tau_{13 m}^{2}\right)} \\
& I_{1 m}=\sigma_{11 m}+\sigma_{22 m}+\sigma_{33 m} \\
& I_{1 a}=\sigma_{11 a}+\sigma_{22 a}+\sigma_{33 a}
\end{aligned}
$$

where $I_{2 \mathrm{a}}$ and $I_{2 \mathrm{~m}}$ are the amplitude and the mean value of the second invariant of the stress deviator tensor, $I_{1 \mathrm{~m}}$ and $I_{1 \mathrm{a}}$ are the amplitude and the mean value of the first invariant of the stress tensor.

The model parameters $A, B, C$ and $D$ were determined as follows:

$$
\begin{aligned}
& A=\frac{1}{\tau_{f}{ }^{\prime}\left(2 N_{e q}\right)^{b o}} ; B=1 / \tau_{u} ; C=\frac{1}{\sigma_{u}}-\frac{1}{\sqrt{3} \tau_{u}} ; D=\frac{1}{\sigma_{f}{ }^{\prime}\left(2 N_{e q}\right)^{b}}-\frac{1}{\sqrt{3} \tau_{f}{ }^{\prime}\left(2 N_{e q}\right)^{b o}} \\
& N_{e q}=\sqrt{N_{\tau} N_{\sigma}} ; N_{\sigma}=\frac{v_{\sigma}}{v_{\tau}} N_{\tau}
\end{aligned}
$$

where $N_{\text {eq }}$ is the equivalent fatigue life, $N_{\sigma}$ and $N_{\tau}$ are values of the predicted fatigue life (normal and shear axis), $\sigma_{\mathrm{u}}$ is the ultimate tensile strength, $\tau_{\mathrm{u}}$ is the shear strength, $\tau_{\mathrm{f}}^{\prime}$ is the shear fatigue strength coefficient, $b_{0}$ is the shear fatigue strength exponent, $\sigma_{\mathrm{f}}^{\prime}$ is the fatigue strength coefficient, $b$ is the fatigue strength exponent, $v_{\sigma}$ and $v_{\tau}$ are load frequencies for normal and shear axis.

Discovering the number of cycles to failure using the Sines ++ model is an iterative process. In this regard, a program was developed in Python software: https://github.com/yanicen1/multiaxial-fatigue-modified-model-Sines-. The prediction results are shown in Tab. 2 and Fig. 3. In addition, the standard error was calculated using the formula:

$$
S E=\sqrt{\frac{\sum_{i=1}^{n}\left(\log \left(N_{p r} / N_{e x}\right)\right)^{2}}{n-2}}
$$

where $n$ is a number of tests.

According to the results of the study, only 1 experimental point out of 28 (or $3.6 \%$ ) lies outside the \pm 2 -factor error and not a single point outside the \pm 3 -factor error. The standard error was 0.175 or \pm 1.5 factors $( \pm 50 \%)$. It should be noted that although the model describes the experimental data quite well, it does not describe the change in the number of cycles when changing the values of the phase shift angle between loading modes, i.e. the predicted number of cycles remains constant (see Tab. 2, loading No. 5-8 and 16-23). However, for the 2024 alloy, this dependence is not essential, which allows the 
Sines ++ model to achieve high accuracy. It is also worth noting that it was proposed to use the equivalent number of cycles $N_{\text {eq }}$ to describe the fatigue behavior of the material at different loading frequencies.

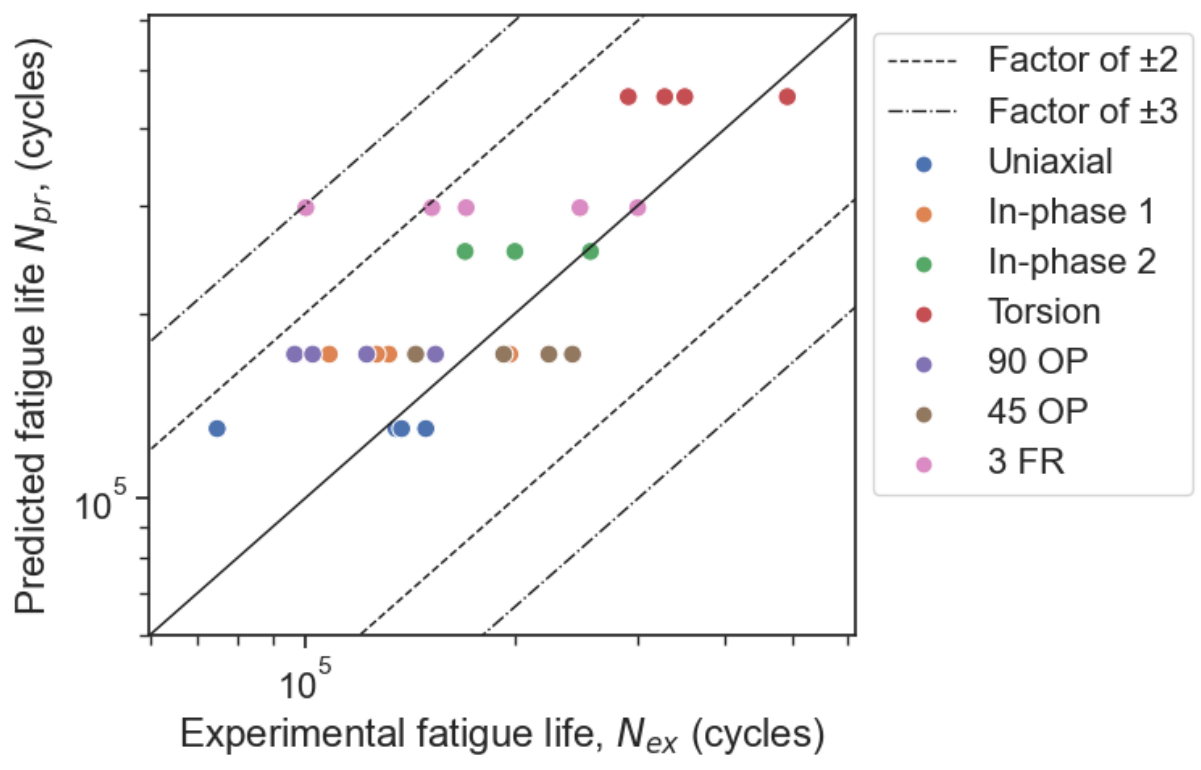

Figure 3: Comparison of model prediction with experimental results

Lastly, it should be noted that for notched bodies modes II and III at the crack tip cannot exist in isolation (for a Poisson's ratio greater than zero): mode II causes mode III and vice versa. These modes are named coupled modes [43, 44]. According to that, considered in this research multiaxial loads might also induce coupled modes. Thus, one should pay attention to this problem in the future dealing with such loads when modes I and III applied in combinations.

\section{CONCLUSIONS}

$\mathrm{I}$ $\mathrm{n}$ the current study, the multiaxial fatigue study was performed to assess the effect of different loading schemes on the fatigue life of the 2024 aluminum alloy under the condition of the same amplitude of the second invariant of the stress deviator tensor in all tests. In the experiments, the phase shift angle between the modes of influence, the ratio of the stress amplitudes of the normal and shear axes, and the ratio of the frequencies of the normal and shear loading axes were varied. As a result, the following conclusions can be summarized from the current research:

1. The loading paths might influence significantly the fatigue life results even if the amplitude of the second invariant of the stress deviator tensor is maintained the same in all tests.

2. A modified Sines fatigue model is proposed for multiaxial fatigue analysis, in which additional material parameters are introduced to describe the patterns of the fatigue behavior observed for the 2024 aluminum alloy.

3. A program for using the modified Sines model is presented that allows determining the number of cycles to failure by means of loading path parameters.

4. For all performed fatigue tests, the modified Sines model demonstrates good fatigue life predictions: only 1 experimental point lies outside the \pm 2 -factor error and not a single point outside the \pm 3 -factor error.

\section{ACKNOWLEDGEMENTS}

he work was carried out in Perm National Research Polytechnic University with the financial support of the Russian Foundation for Basic Research (grants 19-01-00555 A). The experimental studies were conducted within the State Assignment of the Ministry of Science and Higher Education of the Russian Federation (No. FSNM-2020-0027). 


\section{REFERENCES}

[1] Serensen, S.V. (1985). Fatigue of materials and structural elements, Kiev, Naukova dumka.

[2] Troshhenko, V.T. and Sosnovskij, L.A. (1987). Fatigue resistance of metals and alloys, Kiev, Naukova Dumka.

[3] Terent`ev, V.F. and Korableva, S.A. (2015) Metal fatigue, Moscow, Nauka.

[4] Matvienko, Yu.G. (2006). Models and criteria for fracture mechanics, Moscow, Fizmatlit.

[5] Anes, V., Reis, L. and De Freitas, M. (2015). Asynchronous multiaxial fatigue damage evaluation. Proc. Engineering, 101, pp. 421-429. DOI: 10.1016/j.proeng.2015.02.051.

[6] Anes, V., Reis, L. and De Freitas, M. (2015). Multiaxial fatigue damage accumulation under variable amplitude loading conditions. Proc. Engineering, 101, pp. 117-125. DOI: 10.1016/j.proeng.2015.02.016.

[7] Marciniak, Z., Rozumek, D. and Macha, E. (2008). Fatigue lives of 18G2A and 10HNAP steels under variable amplitude and random non-proportional bending with torsion loading, Int. J. Fatigue, 30(5), pp. 800-813.

DOI: 10.1016/j.ijfatigue.2007.07.001.

[8] Shamsei, N., Gladskyi, M., Panasovskyi, K., Shukaev, S. and Fatemi, A. (2010). Multiaxial fatigue of titanium including step loading and load path alteration and sequence effects, Int. J. Fatigue, 32(11), pp. 1862-1874.

DOI: $10.1016 /$ j.ijfatigue.2010.05.006.

[9] Xia, T. and Yao, W. (2013). Comparative research on the accumulative damage rules under multiaxial block loading spectrum for 2024-T4 aluminum alloy, Int. J. Fatigue, 48, pp. 257-265. DOI: 10.1016/j.ijfatigue.2012.11.004.

[10] Sonsino, C.M., Kueppers, M., Eibl, M. and Zhang, G. (2006). Fatigue strength of laser beam welded thin steel structures under multiaxial loading, Int. J. Fatigue, 28(5-6), pp. 657-662. DOI: 10.1016/j.ijfatigue.2005.09.013.

[11] Susmel, L. and Askes, H. (2012). Modified Wohler Curve Method and multiaxial fatigue assessment of thin welded joints, Int. J. Fatigue, 43, pp. 30-42. DOI: 10.1016/j.ijfatigue.2012.01.026.

[12] Li, J., Zhang, Z., Sun, Q. and Li, C. (2011). Multiaxial fatigue life prediction for various metallic materials based on the critical plane approach, Int. J. Fatigue, 33(2), pp. 90-101. DOI: 10.1016/j.ijfatigue.2010.07.003.

[13] Gates, N. and Fatemi, A. (2014). Notched fatigue behavior and stress analysis under multiaxial states of stress, Int. J. Fatigue, 67, pp. 2-14. DOI: 10.1016/j.ijfatigue.2014.01.014.

[14] Zhang, J., Shi, X., Fei, B. (2012). High cycle fatigue and fracture mode analysis of 2A12-T4 aluminum alloy under outof-phase axial-torsion constant amplitude loading, Int. J. Fatigue, 38, pp. 144-154.

[15] Wang Q., Xin C., Sun Q., Xiao L., Sun J. (2018). Biaxial fatigue behavior of gradient structural purity titanium under in-phase and out-of-phase loading, Int. J. Fatigue, 116, pp. 602-609.

[16] Liu, T., Shi, X., Zhang, J., Fei, B. (2019). Crack initiation and propagation of 30CrMnSiA steel under uniaxial and multiaxial cyclic loading, Int. J. Fatigue, 122, pp. 240-255.

[17] Wang Y.-Y., Yao W.-X. (2006). A multiaxial fatigue criterion for various metallic materials under proportional and nonproportional loading, Int. J. Fatigue, 28(4), pp. 401-408.

[18] Skibicki D., Pejkowski L. (2017). Low-cycle multiaxial fatigue behaviour and fatigue life prediction for CuZn37 brass using the stress-strain models, Int. J. Fatigue, 102, pp. 18-36.

[19] Pejkowski, L., Skibicki, D., Seyda, J. (2018). Stress-strain response and fatigue life of a material subjected to asynchronous loadings, AIP Conference Proceeding, 2028, 020016.

[20] Gates, N.R., Fatemi, A. (2017). On the consideration of normal and shear stress interaction in multiaxial fatigue damage analysis, Int. J. Fatigue, 100, pp. 322-336

[21] Wildemann V.E., Tretyakov M.P., Staroverov O.A., Yankin A.S. (2018). Influence of the biaxial loading regimes on fatigue life of 2024 aluminum alloy and 40CrMnMo steel, PNRPU Mechanics Bulletin, 4, pp. 169-177.

DOI: $10.15593 /$ perm.mech/2018.4.16

[22] Sines, G. (1955). Failure of materials under combined repeated stresses with superimposed static stress, Washington, National Advisory Committee for Aeronautics (N.A.C.A), 6.

[23] Mocilnik, V., Gubeljak, N. and Predan, J. (2017). The Influence of a Static Constant Normal Stress Level on the Fatigue Resistance of High Strength Spring SteelTheor. Appl. Fract. Mech., 91, pp. 139-147.

DOI: 10.1016/j.tafmec.2017.06.002.

[24] Papuga, J., Halama, R. (2018). Mean stress effect in multiaxial fatigue limit criteria. Arch. Appl. Mech., pp. 1-12. DOI: $10.1007 /$ s00419-018-1421-7.

[25] Susmel L. Multiaxial notch fatigue: from nominal to local stress-strain quantities. Cambridge, UK: Woodhead; 2009. 
[26] Tovo, R., Lazzarin, P., Berto, F., Cova, M. and Maggiolini, E. (2014). Experimental investigation of the multiaxial fatigue strength of ductile cast iron, Theor. Appl. Fract. Mech., 73, pp. 60-67. DOI: 10.1016/j.tafmec.2014.07.003.

[27] Pallarés-Santasmartas, L., Albizuri, J., Avilés, A., Saintier, N. and Merzeau, J. (2018). Influence of mean shear stress on the torsional fatigue behaviour of 34CrNiMo6 steel, Int. J. Fatigue, 113, pp. 54-68.

DOI: $10.1016 /$ j.ijfatigue.2018.04.008.

[28] Fatemi A, Socie D.F. (1988). A critical plane approach to multiaxial fatigue damage including out-of-phase loading, Fatigue Fract. Engng Mater. Struct. 1(3), pp. 149-165.

[29] Smith RN, Watson P, Topper TH. (1970). A stress-strain parameter for the fatigue of metals. J. Mater, 5(4), pp. 767778.

[30] Brown MW, Miller KJ. (1973). A Theory for Fatigue Failure under Multiaxial Stress-Strain Conditions, Proc Inst Mech Eng, 187, pp. 745-755.

[31] Crossland B. (1956). Effect of large hydrostatic pressures on the torsional fatigue strength of an alloy steel, In Proceedings of the International Conference on Fatigue of Metals (Institution of Mechanical Engineers, London), pp. 138-149.

[32] Ince A, Glinka G. (2014). A generalized fatigue damage parameter for multiaxial fatigue life prediction under proportional and non-proportional loadings, Int. J. Fatigue, 62(2), pp. 34-41. DOI: 10.1016/j.ijfatigue.2013.10.007 .

[33] Zhu, S.-P., Yu, Z.-Y., Correia, J., De Jesus, A., and Berto, F. (2018). Evaluation and comparison of critical plane criteria for multiaxial fatigue analysis of ductile and brittle materials, Int. J. Fatigue, 112, pp. 279-288. DOI: 10.1016/j.ijfatigue.2018.03.028.

[34] Correia, J., Apetre, N., Arcari, A., De Jesus, A., Muñiz-Calvente, M., Calcada, R., Berto, F. and Fernández-Canteli, A. (2017). Generalized probabilistic model allowing for various fatigue damage variables, Int. J. Fatigue, 100, pp. 187-194. DOI: 10.1016/j.ijfatigue.2017.03.031.

[35] Milella P. P. (2013). Fatigue and Corrosion in Metals, Springer, 844 p.

[36] Carpinteri, A., Spagnoli, A., and Vantadori, S. (2017). A review of multiaxial fatigue criteria for random variable amplitude loads, Fatigue Fract. Engng Mater. Struct, 40(7), pp. 1007-1036. DOI: 10.1111/ffe.12619.

[37] Yankin A.S. et alii. (2020). Influence of static mean stresses on the fatigue behavior of 2024 aluminum alloy under multiaxial loading, Frattura ed Integrità Strutturale, 14(51), pp. 151-163. DOI: 10.3221/IGF-ESIS.51.12.

[38] Xia T.X., Yao W.X., Ji Y.F., Wang C.J. (2015). Study on the accumulative fatigue damage rules under multiaxial twostage step spectra constructed by loadings with similar lives, Fatigue Fract. Engng Mater. Struct, 38(7), pp. 838-850.

[39] Han Z.-Y., Huang X.-G., Cao Y.-G., Xu J.-Q. (2014). A nonlinear cumulative evolution model for corrosion fatigue damage, Journal of Zhejiang University: Science A, 15(6), pp. 447-453.

[40] Chang H., Pang X.C., Li Z.J., Tang W.J., Chen F.M. (2014). Monitoring corrosion fatigue damage process of LY12CZ aluminum alloy with and without coating by acoustic emission, Applied Mechanics and Materials, 552, pp. 145-148.

[41] Wang Y., Zhang D., Yao W. (2014). Fatigue damage rule of LY12CZ aluminium alloy under sequential biaxial loading, Science China: Physics, Mechanics and Astronomy, 57(1), pp. 98-103.

[42] Wang, X.-W., Shang, D.-G. (2016). Determination of the critical plane by a weight-function method based on the maximum shear stress plane under multiaxial high-cycle loading, Int. J. Fatigue, 90, pp. 36-46.

[43] Pook, L. P., Campagnolo, A., and Berto, F. (2016). Coupled fracture modes of discs and plates under anti-plane loading and a disc under in-plane shear loading, Fatigue Fract. Engng Mater. Struct, 39(8), pp. 924-938.

DOI: $10.1111 /$ ffe.12389.

[44] Berto, F., Lazzarin, P., and Kotousov, A. (2011). On higher order terms and out-of-plane singular mode, Mechanics of Materials, 43(6), pp. 332-341. DOI: 10.1016/j.mechmat.2011.03.004. 